\title{
An integrated three-dimensional model of wave-induced pore pressure and effective stresses in a porous seabed: II. Breaking waves
}

\author{
D.-S. Jeng ${ }^{*}, 1$ and H. Zhang ${ }^{2}$ \\ ${ }^{1}$ Department of Civil Engineering, The University of Sydney, New South Wales 2006, Australia \\ ${ }^{2}$ School of Engineering, Griffith University, Gold Coast Campus, Queensland 9726, Australia
}

Final version for Ocean Engineering, 14 January 2005

\begin{abstract}
The elevation of the wave-induced liquefaction potential is particularly important for coastal engineers involved in the design of marine structures. Most previous investigations of the wave-induced liquefaction have been limited to two-dimensional non-breaking waves. In this paper, the integrated three-dimensional poro-elastic model for the wave-seabed interaction proposed by Zhang and Jeng (2005) is further extended to simulate the seabed liquefaction potential with breaking wave loading. Based on the parametric study, we conclude: (1) the liquefaction depth due to breaking waves is smaller than that of due to non-breaking waves; (2) the degree of saturation significantly affect the wave-induced liquefaction depth, and no liquefaction occurs in full saturated seabed, and (3) soil permeability does not only significantly affect the pore pressure, but also the shear stresses distribution.

Keywords: Breaking wave loading, Pore pressure, Effective stresses, Liquefaction,
\end{abstract}

\footnotetext{
* Author to whom all correspondence should be addressed. Email addresses: d.jeng@civil.usyd.edu.au (D-S Jeng) hon.zhang@griffith.edu.au (H. Zhang)
} 


\section{Introduction}

The phenomenon of the wave-induced liquefaction is an important feature in numerous coastal engineering problems such as stability of breakwaters and sinking or uplift of pipelines. In general, when ocean waves propagates over a porous seabed, the dynamic wave pressure acting on the seabed surface will further induce excess pore pressure and effective stresses within the soil matrix. When the excess pore pressure increases to a certain level, the seabed may be liquefied, then, the foundation around coastal structure will become unstable and further cause the instability of the structure.

Numerous investigations for the wave-induced seabed response have been carried out since the 1970’s. Among these, analytical approximations such as Jeng (1997), numerical modeling such as Lin and Jeng (2000), and experimental work such as Sumer et al. (1999) and Sassa et al. (2001) have been used to investigate the wave-induced liquefaction potential. The contributions and limitation of previous studies in the area have been systematically reviewed in Jeng (2003). However, all previous models have been limited to two-dimensional cases, which can only represent part of the whole problem. Thus a three-dimensional model for such a problem is desired.

Recently, a three-year EU program "Liquefaction around Marine Structures (LIMAS)” (http://vb.mek.dtu.dk/research/limas/limas.html) has been carried out during 2001-2004. The program has been undertaken by a consortium of 10 institutes, including universities, hydraulics and geotechnical engineering laboratory and consulting companies. The program covers several topics: physics of liquefaction around marine structures; soil liquefaction around and its impactions for marine pipelines; wave-induced soil liquefaction around and its implication for caisson breakwaters; seismic-induced liquefaction around marine structures; and 
mathematical modeling of soil liquefaction. Again, the research work involved in LIAMS has also been limited to two-dimensional cases. Thus, a three-dimensional model for such a problem is desired.

This is the consequent paper of the first paper (Zhang and Jeng, 2005). In the first paper, an integrated model, incorporating wave and soil models, was proposed to investigate the wave-induced pore pressure and effective stresses in a porous seabed. The main focus of the paper (Zhang and Jeng, 2005) was the wave-induced soil response with non-breaking wave loading. In this paper, the previous model is further extended to breaking wave conditions. Based on the proposed model, the breaking wave-induced liquefaction in Gold Coast region will be investigated.

\section{Integrated model for breaking waves}

\subsection{Breaking wave model}

SWAN (Simulating Waves Near-shore) is a numerical model, which provides estimations of the wave parameters in coastal areas, lakes and estuaries with given wind, bottom and current conditions. It is a spectral wave model based on the action density balance equation (Booij et al., 1999; Ris et al., 1999), which calculates wave transformation and set up. The version (Cycle 3, version 40.20) used in present study is the time dependent version released to public in 2003. Since details of SWAN with non-breaking waves were given in Zhang and Jeng (2005), we only summarise the breaking model in SAWN in this section.

From the modeling point of view, the direct effect of dissipation is a reduction in wave height. The dissipation form of wave energy can be expressed in terms of three different contributions. They are: whitecapping, bottom friction and depth-induced breaking. The detailed information for the wave energy dissipation can be found in Holthusijsen et al. (2003). 
The depth-induced breaking is a complicated process which can be quantified poorly. Its spectral modeling has not been established. However, the total dissipation due to this type of wave breaking can be well modeled with the dissipation of bore applied to the breaking waves in a random field (Battjes and Janssen,1978; Thornton and Guza, 1983). The depth-induced breaking included in the current model can be expressed as

$$
\mathrm{S}_{\mathrm{ds}, \mathrm{br}}(\sigma, \theta)=\frac{\mathrm{D}_{\mathrm{tot}}}{E_{\text {tot }}} E(\sigma, \theta)
$$

in which $E_{\text {tot }}$ is the total wave energy and $D_{\text {tot }}$ is the rate of dissipation of the total energy due to wave breaking. $D_{\text {tot }}$ critically depends on the breaking parameter which is the ratio of the maximum wave height and the water depth. To model the energy dissipation in random waves due to depth-induced breaking, the bore-based model of Battjes and Janssen (1978) is used in SWAN. The mean rate of energy dissipation per unit horizontal area due to wave breaking $D_{\text {tot }}$ is expressed as:

$$
D_{\text {tot }}=-\frac{1}{4} Q_{b}\left(\frac{\bar{\sigma}}{2 \Pi}\right) H_{m}^{2}
$$

where $\mathrm{Q}_{\mathrm{b}}$ is the fraction of breaking wave and $\bar{\sigma}$ is a mean frequency, which are determined by

$$
\frac{1-Q_{b}}{\ln Q_{b}}=-8 \frac{E_{\text {tot }}}{H_{m}^{2}} \quad \text { and } \quad \bar{\sigma}=E_{\text {tot }}^{-1} \int_{0}^{2 \pi} \int_{0}^{\infty} \sigma E(\sigma, \theta) d \sigma d \theta
$$

in which $\mathrm{H}_{\mathrm{m}}$ is the maximum wave height that can exist at the given depth.

\subsection{Liquefaction}

Recently, the first author has developed a series of analytical solutions and numerical models for the wave-induced seabed response around marine structures, based on Biot's poro-elastic theory (Biot, 1941). In this study, we adopted the solutions of the short-crested wave-induced soil response in am infinite seabed with the wave model (SWAN) to examine the wave-induced liquefaction in a three-dimensional coastal region. Details of the soil model were given in the first paper (Zhang and Jeng, 2005).

To apply the concept of excess pore pressure to a porous seabed, Figure 1 illustrates the vertical distribution of the pore pressure and effective stresses. In this 
figure, the solid curves indicate the pore pressure beneath wave troughs and wave crests. Since the excess pore pressure is transient in nature, the effective stresses also vary periodically in accordance with the change of the excess pore pressure. If zero or a negative value of the vertical effective stress is attained at certain depth below the seabed surface, the soil skeleton will be subjected to the action of a net pressure force in the vertical direction. The seabed may fail to carry any vertical load and be liquefied (Figure 1(b)). Thus, the criterion for the wave-induced liquefaction can be expressed as (Jeng, 1997)

$$
-\frac{1}{3}\left(\gamma_{s}-\gamma_{w}\right)\left(1+2 K_{o}\right) z+\left(P_{b}-p\right) \leq 0
$$

where $P_{b}$ is the wave pressure at the seabed surface and $p$ is the wave-induced pore pressure, $\gamma_{s}$ and $\gamma_{w}$ are the unit weight of soil and water, respectively. $K_{o}$ is the coefficient of lateral earth pressure at rest which varies from 0.4 to 1.0, depending on the marine sediments.

\section{$\underline{\text { [Figure } 1 \text { near here] }}$}

\section{Numerical examples: Case study at Gold Coast}

\subsection{Wave field at Gold Coast}

In this study, the coastal region at Gold Coast is used as a case study. The calculated domain covers the latitude from S28 to S29, and the longitude from E153.3 to E153.7. The water depth varies from shallow water to deep water (up to $120 \mathrm{~m}$ ), as shown in Figure 2. With the provided bathymetry and a southeast wind of $20 \mathrm{~m} / \mathrm{s}$, the distribution of wave heights and wave directions calculated from the wave model (SWAN) is plotted in Figure 3. The distributions of the wavelength and peak wave frequency are presented in Figures 4 and 5, respectively. The comparisons between 
wave breaking and non-wave breaking conditions are included. The input data of soil characteristics, wind conditions and the grid size used in the wave model is given in Table 1.

[Figure 2 near here]

[Figure 3 near here]

[Figure 4 near here]

[Figure 5 near here]

[Table 1 near here]

\subsection{Comparison between non-breaking and breaking waves}

Since this paper is the first to include breaking wave loading into the wave-seabed interaction problem, it is necessary to compare the results between non-breaking and breaking waves. The contours of the wave-induced pore pressure at $z=-1 \mathrm{~m}$ and $t=3.25 \mathrm{sec}$ are plotted in Figure 6. Both non-breaking and breaking waves are presented in the figure. As seen in Figure 6, the magnitude of the wave-induced pore pressures under non-breaking wave loading is slightly greater than that under breaking wave loading. The distribution of the pore pressure and location of the maximum magnitudes are also different. For example, the maximum value of pore pressure (negative) under breaking wave loading is located near (E153.65, S28.4), while that under non-breaking wave loading is located near (E153.65, S28.05). This difference will affect the location of the maximum liquefied depth, which is important for the design of marine structure. 


\section{[Figure 6 near here]}

It is also necessary to investigate the distributions of the wave-induced pore pressure and shear stresses versus time at a particular point (see Figure 7). In this example, we choose Point A, indicated in Figure 2, as a numerical example. In the figure, the solid lines represent the results under non-breaking wave loading, while the lines with symbols represent the results under breaking wave loading. Figure 7 indicates that there is a phase lag of the wave-induced soil response under non-breaking and breaking wave loadings. It is clear that the wave-induced pore pressure and shear stresses under non-breaking wave loading are greater than that under breaking loading. However, this result depends on the location we choose (i.e. Point A). There will have different results, if we choose another location.

\section{[Figure 7 near here]}

Figure 8(a) illustrates the contour distribution of the liquefaction depth at $t=3.25$ sec with and without wave breaking. As shown in the figure, the maximum liquefied depth without wave breaking is about $2.5 \mathrm{~m}$, which is almost twice of that with wave breaking $(1.25 \mathrm{~m})$. Another important result is observed is that the locations of holes generated by liquefaction under non-breaking and breaking waves are different.

It is also interesting to examine the liquefied profile at Point $\mathrm{A}$ under non-breaking and breaking waves. The wave frequencies for non-breaking are smaller than that with breaking waves, but the wave height is greater. It is observed from Figure 8(b), the liquefied area under breaking waves is shallow and narrow, compared with that under non-breaking waves. 


\section{[Figure 8 near here]}

\subsection{Effects of the degree of saturation}

The degree of saturation has been recognised as an important parameter in the estimation of the wave-induced liquefaction. In most marine sediments, the degree of saturation varies between 95\% and 100\% (fully saturation) (Okusa, 1985). In this example, four values of the degree of saturation are chosen, they are: 0.95, 0.97, 0.99 and 1.0. Figure 9 illustrates the contour of the wave-induced pore pressure in Gold Coast region at $z=-1 \mathrm{~m}$. As shown in the figure, the degree of saturation significantly affects the magnitude of the wave-induced pore pressure, especially nearly saturation.

Figure 10 presents the distribution of the wave-induced pore pressure and shear stresses versus time at Point A. Again, significant effects of the degree of saturation are observed in Figure 10. It is noted that the results presented in Figure 10(a) is the wave-induced pore pressure $(p)$. According to the definition of liquefaction, (1), liquefaction will occur when the excess pore pressure $\left(u_{e}=p-P_{b}\right)$ is greater than the

self-weight of the soil $\left[-\frac{\left(1+2 K_{0}\right)}{3}\left(\gamma_{s}-\gamma_{w}\right) z\right]$. Since liquefaction usually occurs near wave troughs, a smaller negative magnitude of pore pressure near wave troughs will be more likely to have liquefaction occur because the excess pore pressure will be greater. Therefore, it is more likely to observed liquefaction in unsaturated seabed, rather than saturated seabed.

Contours of the wave-induced liquefaction depth with different values of the degree of saturation are illustrated in Figure 11(a). As shown in the figure, no liquefaction occurs in a fully saturated seabed, which confirms the previous finding by Jeng (1997) that momentary liquefaction only occurs in an unsaturated seabed. It is also found in Figure 11(a), liquefaction only occurs in the region near the coastline at 
time $t=3.25 \mathrm{sec}$. It is also observed that the maximum liquefaction depth increases as the degree of saturation decreases (see Figure 11(b)).

[Figure 9 near here]

[Figure 10 near here]

[Figure 11 near here]

\subsection{Effects of soil permeability}

Soil permeability (also called hydraulic conductivity) is a measure to indicate how fast the pore fluid transfers between a porous medium. It has been commonly used to classify the type of soil, together with other soil parameters such as shear modulus and Poisson's ratio.

Figure 12 presents the contours of the wave-induced pore pressure in a porous seabed with different soil permeabilities ( $K_{z}=10^{-2}$ and $10^{-4} \mathrm{~m} / \mathrm{sec}$ ). The contours distributions of pore pressure with two different materials are significantly different. For a coarse seabed ( $K_{z}=10^{-2} \mathrm{~m} / \mathrm{sec}$ ), some positive values of the pore pressure are observed in Figure 12, while only negative values of pore pressure are observed in finer seabed $\left(K_{z}=10^{-4} \mathrm{~m} / \mathrm{sec}\right.$ ). This significant difference in phase lag can be explained by the fact that the pore fluid transfer faster in coarse seabed, which may cause consolidation in some regions near the coastline.

\section{[Figure 12 near here]}

Distributions of the wave-induced pore pressure and shear stresses versus time 
for various soil permeabilities are illustrated in Figure 13. Unlike the effects of the degree of saturation, soil permeability does not only significantly affect the pore pressure, but also the shear stresses. This influence will further affect the wave-induced liquefaction potential, as shown in Figure 14.

\section{[Figure 13 near here]}

The wave-induced liquefaction potentials for two different materials are presented in Figure 14(a). As shown in the contour plots, the wave-induced liquefaction is more likely to occur in fine sand seabed $\left(K_{z}=10^{-4} \mathrm{~m} / \mathrm{sec}\right)$, compared with coarse sand seabed ( $K_{z}=10^{-2} \mathrm{~m} / \mathrm{sec}$ ). Also, the maximum liquefaction depth in fine sand is greater than that in coarse sand (see Figure 14(b)).

\section{[Figure 14 near here]}

\section{Conclusions}

In this paper, the breaking wave-induced soil response (including pore pressure and shear stresses) was examined with the case study at Gold Coast. The wave-induced liquefaction potential in a porous seabed was also investigated. Based on the numerical results, the following conclusions can be drawn:

(1) The breaking wave-induced soil response performs with different phases, compared with the cases of non-breaking wave. Also, the maximum liquefactions due to breaking waves are reduced significantly compared to that due to non-breaking waves.

(2) The degree of saturation significantly affects the wave-induced pore pressure and liquefaction potential. There is no liquefaction in full saturated seabed. In general, the maximum liquefied depth increases as the degree of saturation decreases. 
(3) Soil permeability does not only significantly affect the pore pressure, but also the shear stresses, as shown in Figure 13. Basically, the maximum liquefaction increases as the soil permeability decreases.

\section{Acknowledgements}

The first author is grateful for the support of Australian Research Council Large Grant Scheme \#A00104092 (2001-2003).

\section{References}

Battjes and Janssen (1978). Energy loss and set-up due to breaking of random waves, Proc. 16th Int. Conf. Coatal Engineering, ASCE, 569-587.

Biot, M. A. (1941). General theory of three-dimensional consolidation. Journal of Applied Physics, 12, 1550164

Booij, N., Ris, R. C., Holthuijsen, L. H. (1999). A third-generation wave model for coastal regions. Part I, Model description and validation. Journal of Geophysical Research, 104, 7649-7666.

Holthuijsen, L. H., Booij, N. Ris, R. C., Haagsma, I. J. G., Kieftenburg, A. T. M. M., Kriezi, F. E. (2003). SWAN Cycle III Version 40.20 User Manual. Delft University of Technology, The Netherlands.

Jeng, D.-S. (1997). Wave-induced seabed instability in front of a breakwater. Ocean Engineering, 24, 887-917.

Jeng, D.-S. (2003). Wave-induced seafloor dynamics. Applied mechanics Review, 56, $407-429$

Lin, Y.S. and Jeng, D.-S. (2000). Short-crested wave-induced liquefaction in porous seabed. Journal of Geotechnical and Geoenvironmental Engineering, A.S.C.E., 126(5), 481-494 
Okusa, S (1985). Wave-induced stress in unsaturated submarine sediments. Geotechnique, 35(4), 517-532.

Ris, R. C., Holthuijsen, H., Booij, N. (1999). A third-generation wave model for coastal regions, Part II, Verification. Journal of Geophysical Research, 104, 7667-7681.

Sassa, S, Sekiguchi, H. and Miyamamot, J. (2001), Analysis of progressive liquefaction as moving-boundary problem. Geotechnique, 51(10), 847-857.

Sumer, B. M., Fredsoe, J., Christensen, S. and Lind, M. T. (1999). Sinking/floating of pipelines and other bjectives in liquefied soil under waves. Coastal Engineering, 38(2), 53-90.

Thornton, E.B. and Guza, R.T. (1983): Transformation of wave height distribution, Journal of Geophysical Research, 88, C10, 5925-5938

Zhang, H. and Jeng, D.-S. (2005). An integrated three-dimensional model of wave-induced pore pressure and effective stresses in a porous seabed: I. A sloping seabed. Ocean Engineering (in press) 


\section{Figure captions}

Figure 1: $\quad$ Concept of excess pore pressure and liquefaction.

Figure 2: $\quad$ Bathymetry in Gold Coast.

Figure 3: Distributions of wave heights and wave direction at Gold Coast with and without breaking waves.

Figure 4: $\quad$ Distributions of wave lengths at Gold Coast with and without breaking waves.

Figure 5: $\quad$ Distributions of peak wave frequencies at Gold Coast with and without breaking waves.

Figure 6: Distribution of the wave-induced pore pressures in a porous seabed with and without wave breaking at $t=3.25 \mathrm{sec}$.

Figure 7: $\quad$ Time series of the wave-induced pore pressure and shear stresses versus time $(t)$ with and without wave breaking at Point A.

Figure 8: (a) Contours of the wave-induced liquefaction with and without wave breaking, (b) Distribution of the wave-induced liquefied zone with and without wave breaking at Point A.

Figure 9: $\quad$ Contours of the breaking wave-induced pore pressures in a porous seabed for various degree of saturation at $t=3.25 \mathrm{sec}$.

Figure 10: Time series of the breaking wave-induced pore pressure and shear stresses versus time $(t)$ for various degree of saturation at Point A.

Figure 11: (a) Contours of the breaking wave-induced liquefaction for various degrees of saturation, (b) Distribution of the breaking wave-induced liquefied zone for various degrees of saturation at Point A.

Figure 12: Contours of the breaking wave-induced pore pressures in a porous seabed for various values of soil permeability at $t=3.25 \mathrm{sec}$.

Figure 13: Time series of the breaking wave-induced pore pressure and shear 
stresses versus time $(t)$ for various values of soil permeability at Point A.

Figure 14: $\quad$ (a) Distributions of the breaking wave-induced liquefaction for various values of soil permeability, (b) Time series of the breaking wave-induced liquefied zone for various values of soil permeability at Point A. 


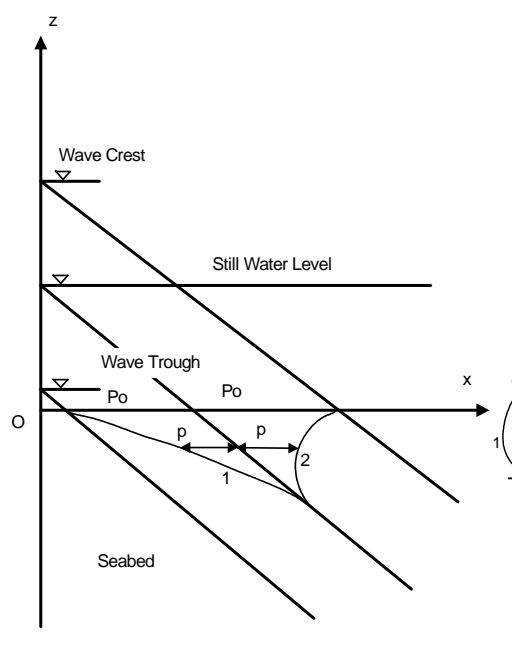

(a)

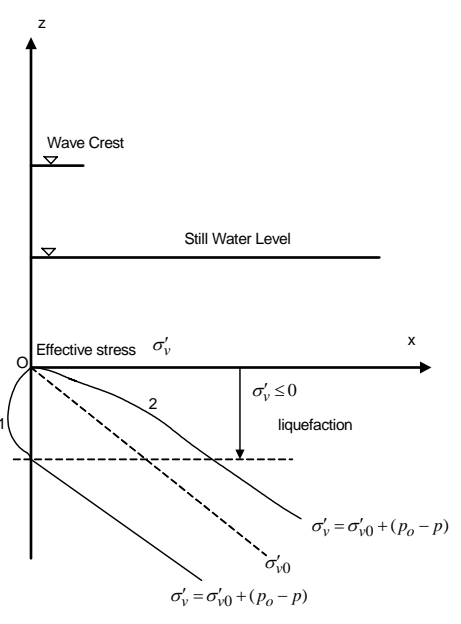

(b)

Figure 1 


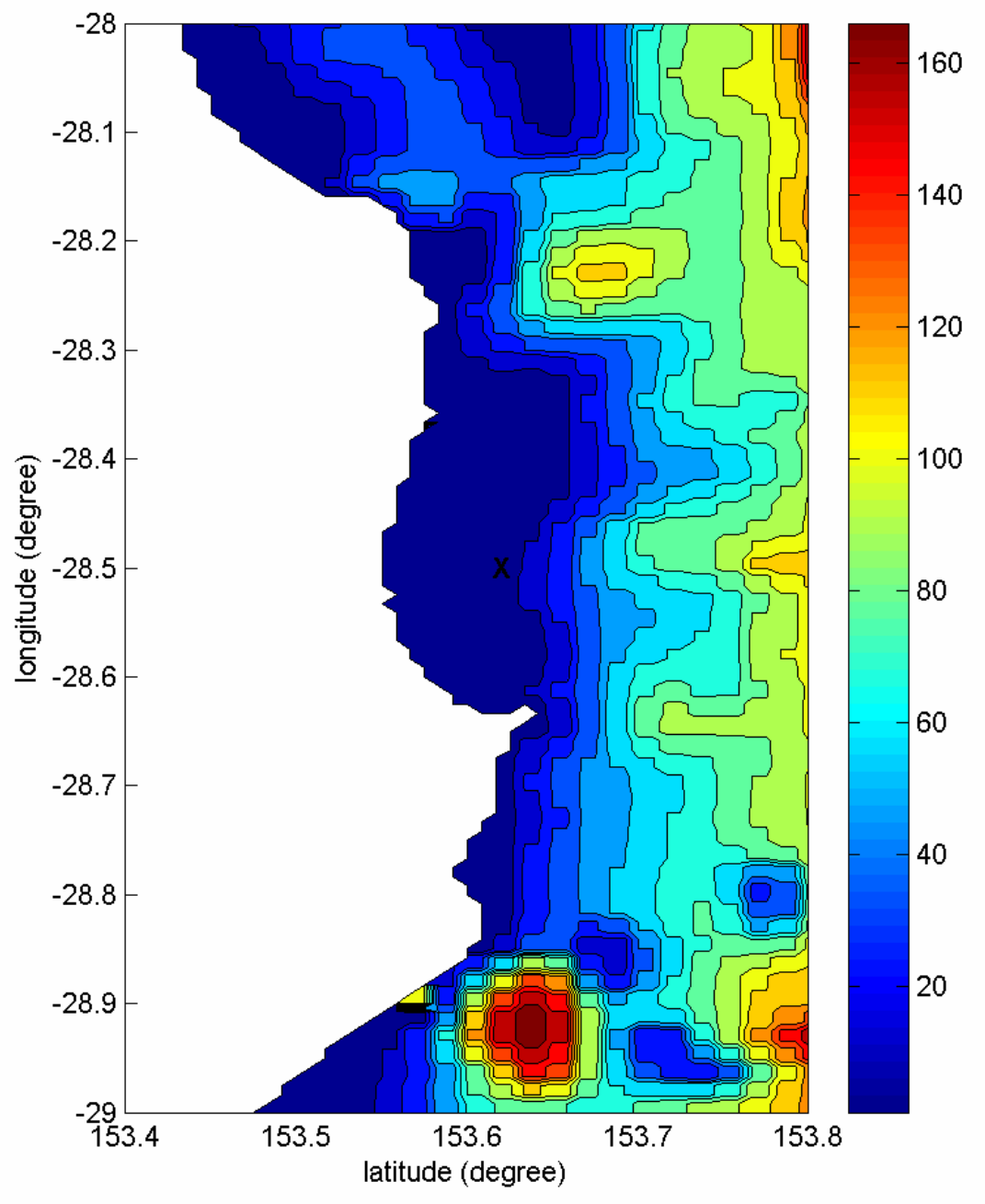

Figure 2 

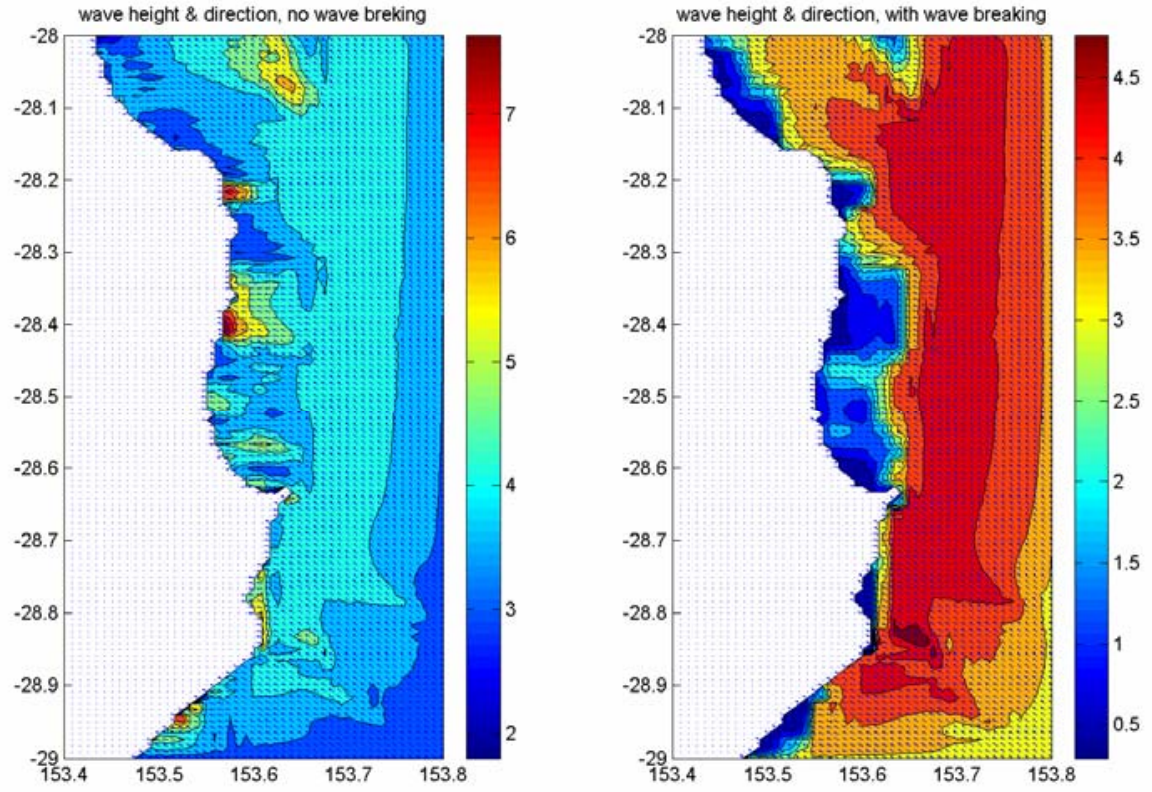

Figure 3 

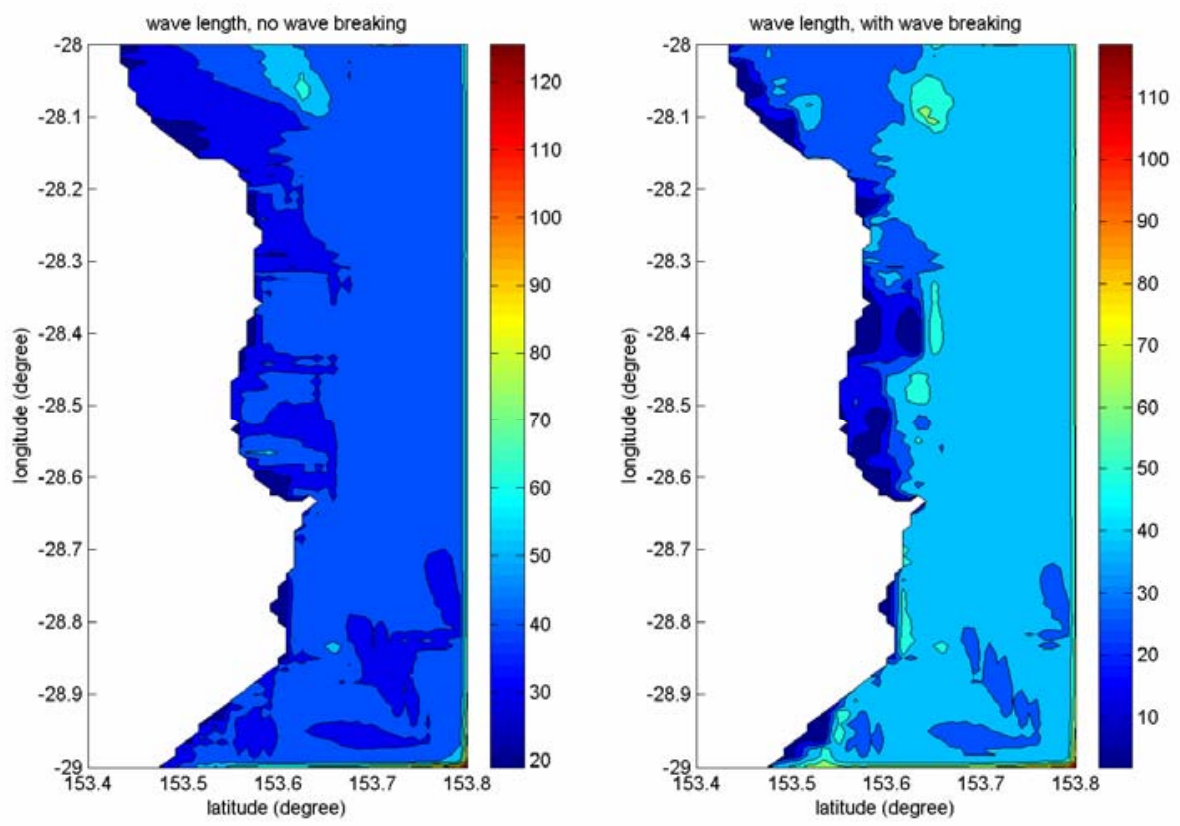

Figure 4 

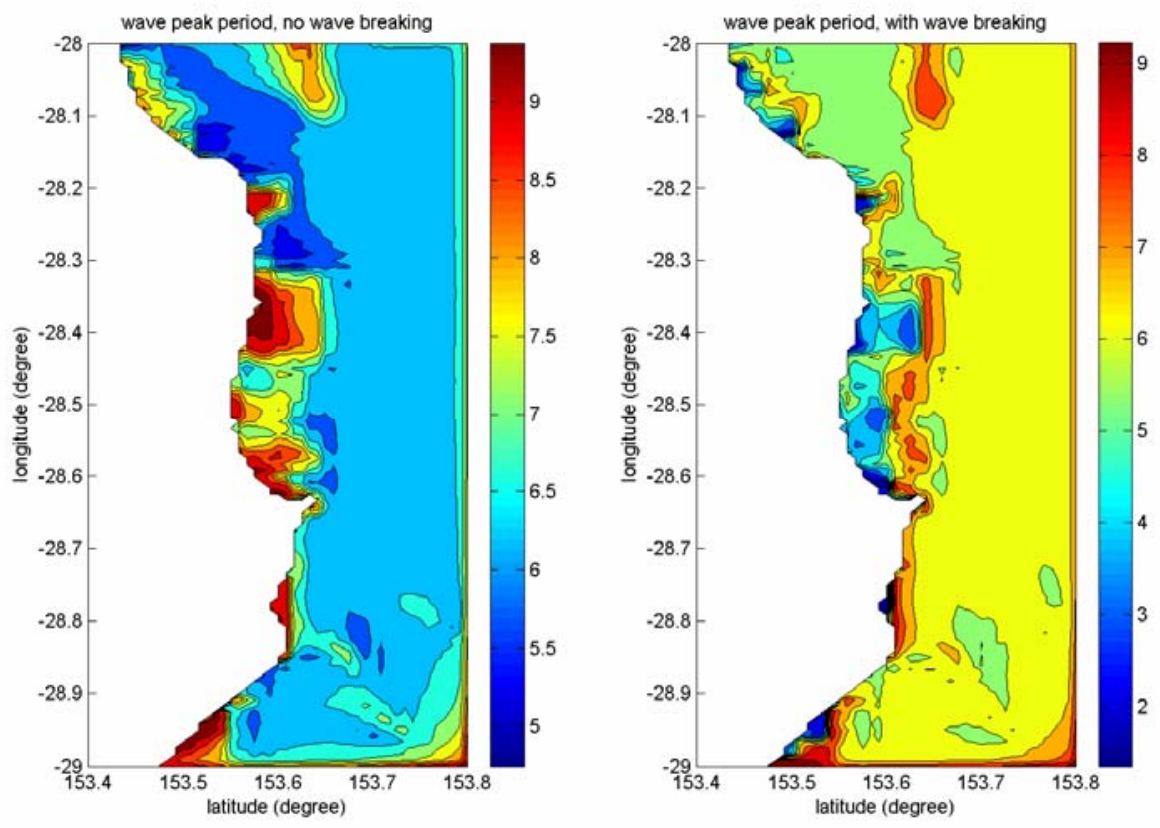

Figure 5 

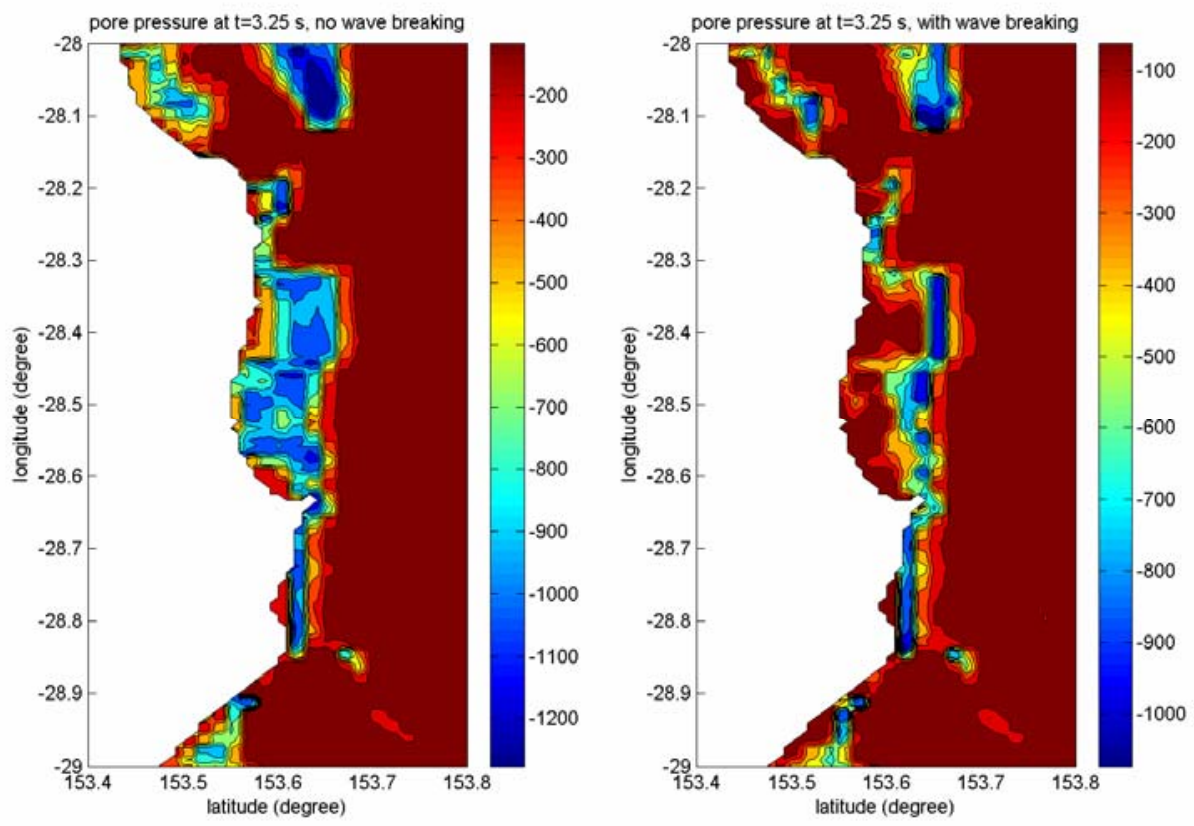

Figure 6 


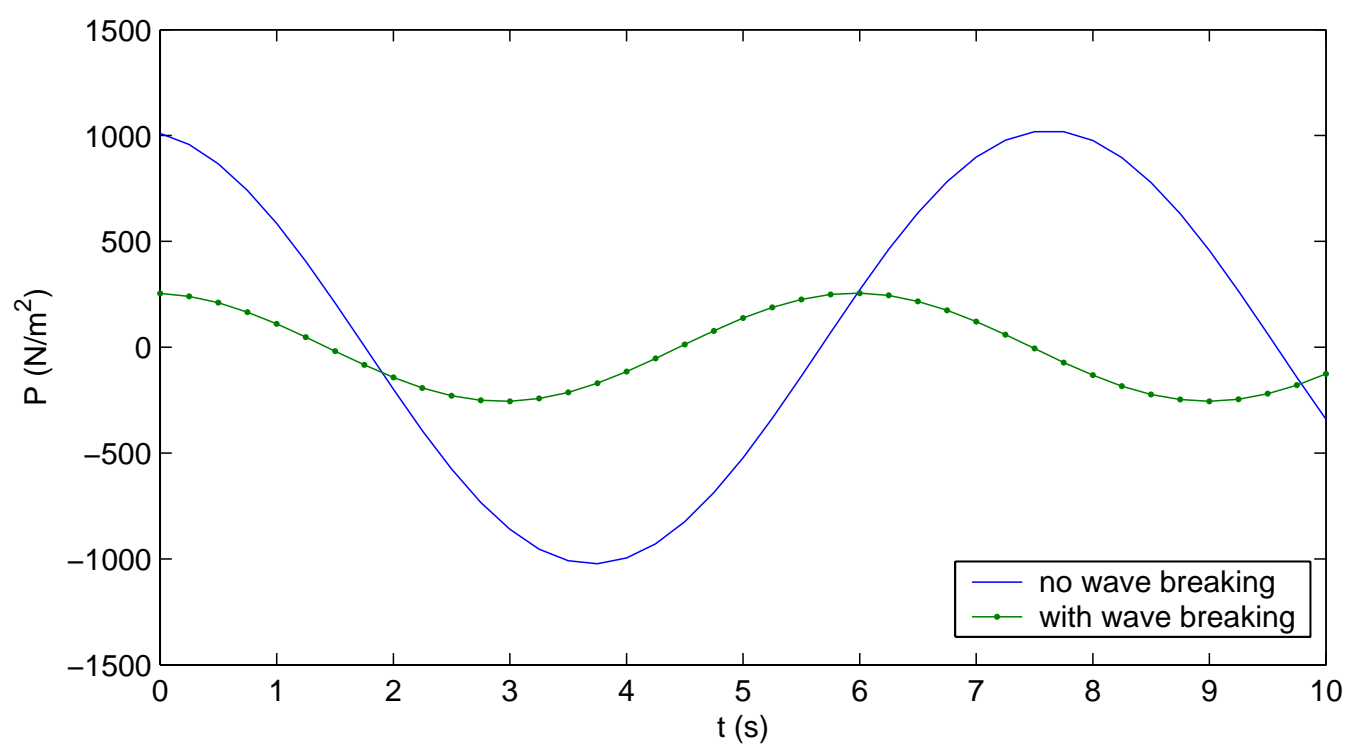

Figure 7(a)

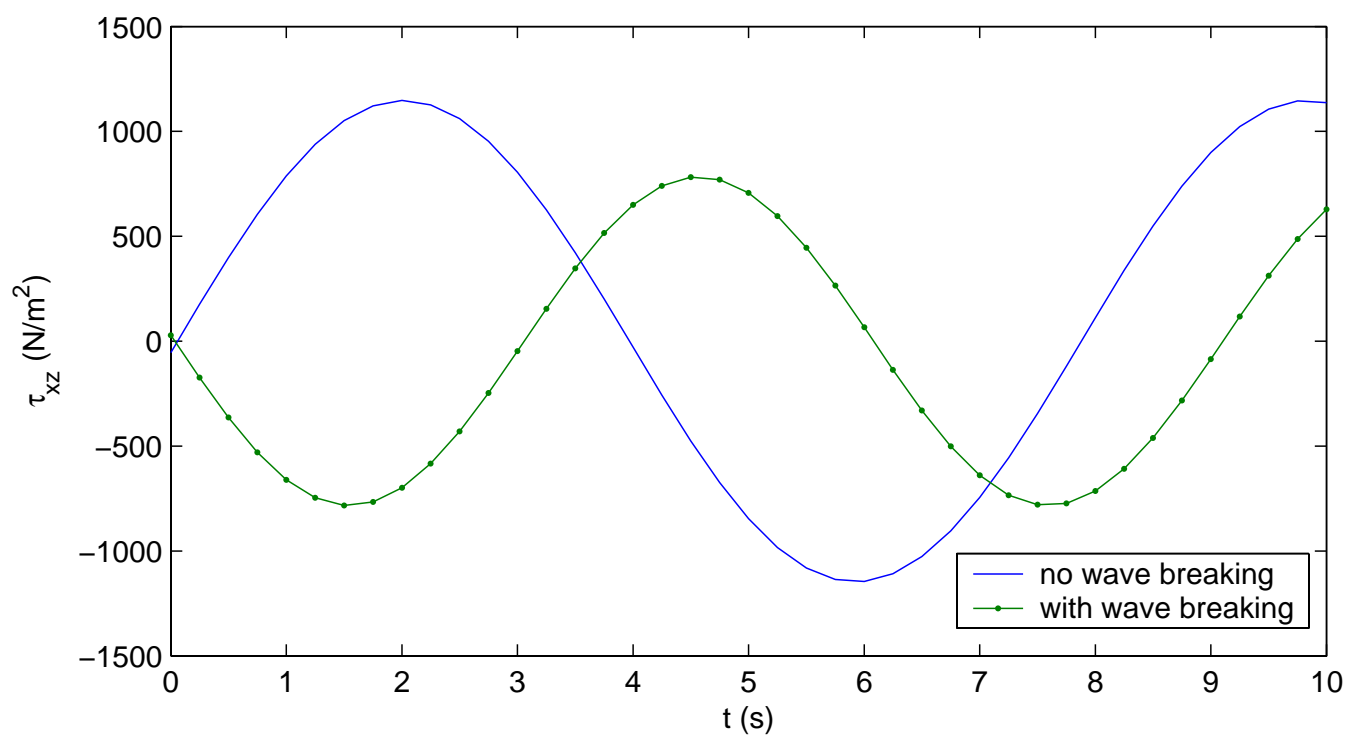

Figure 7(b) 


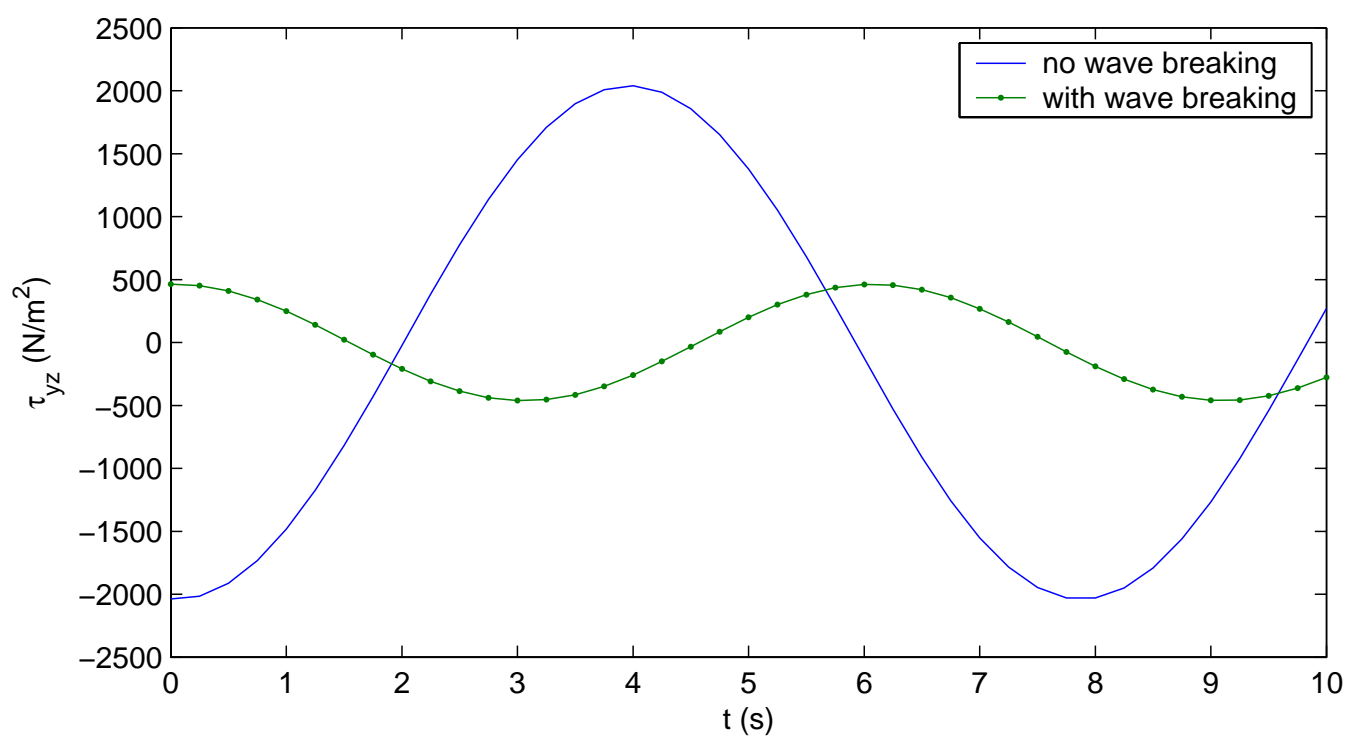

Figure 7(c)

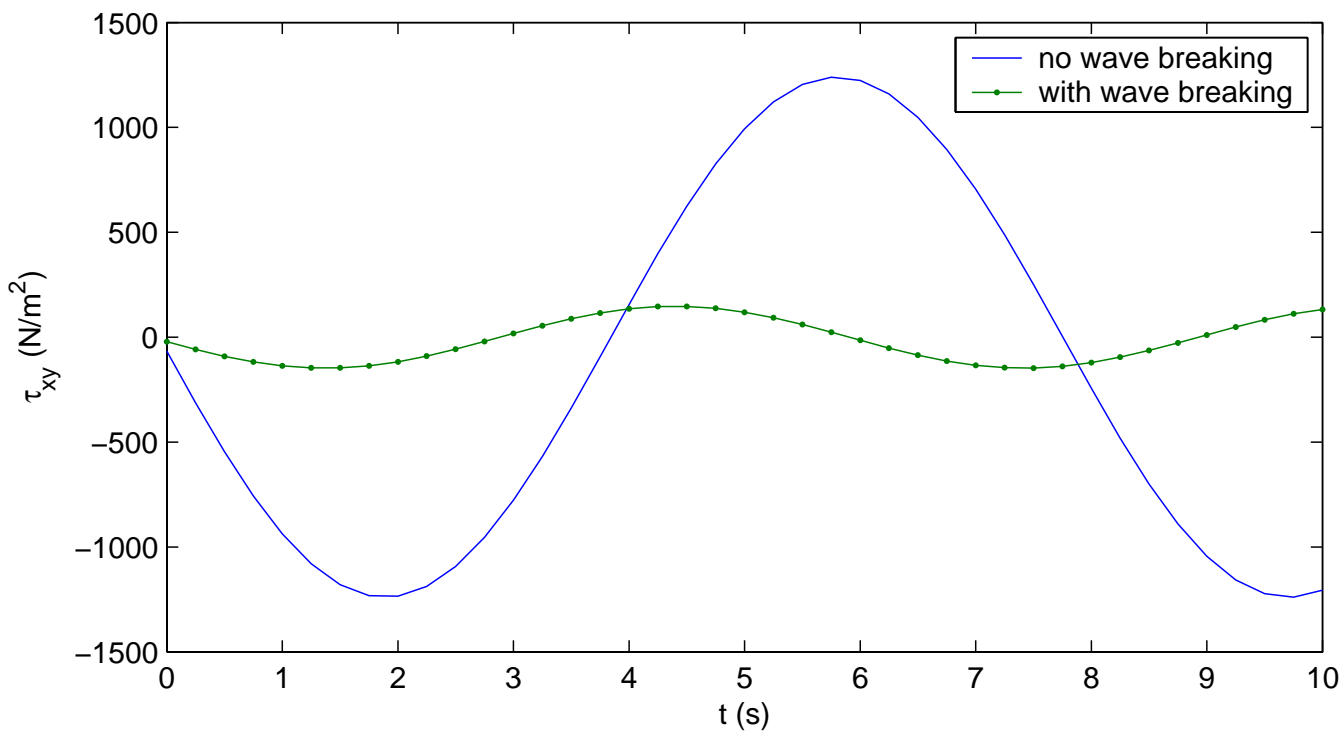

Figure 7(d) 

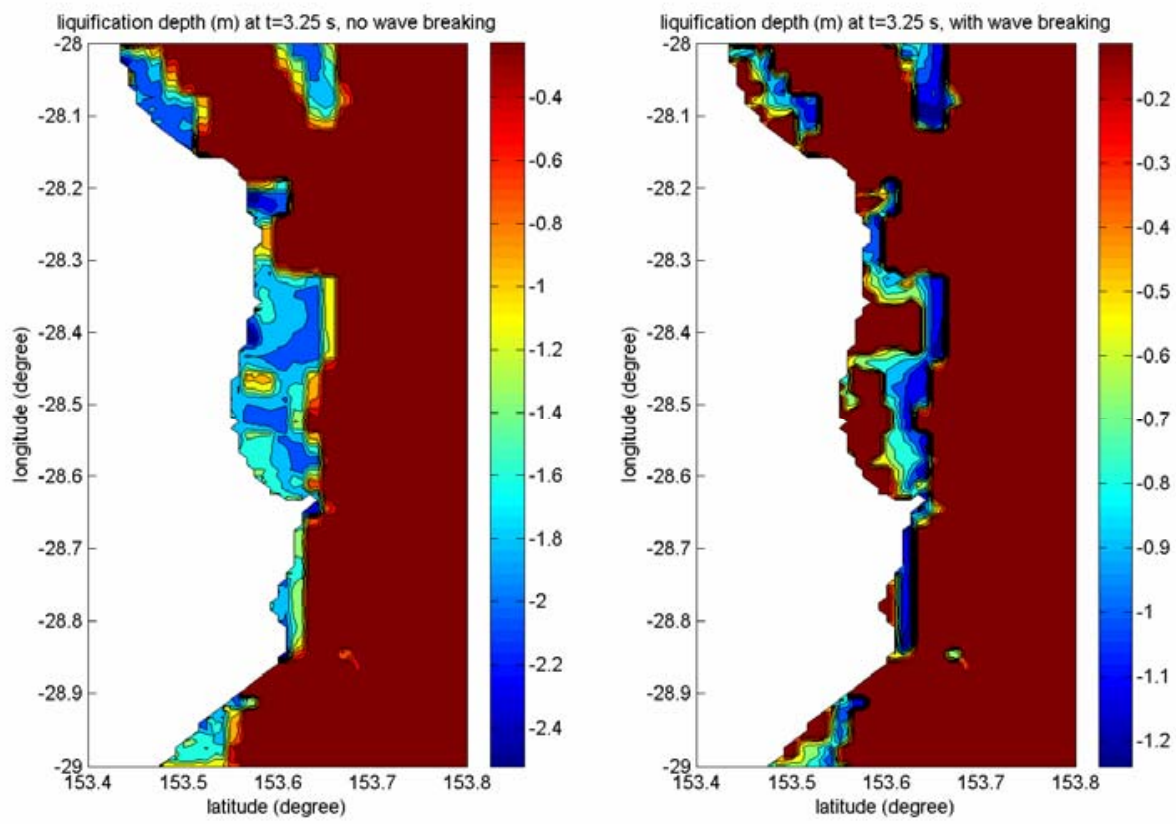

Figure 8(a)

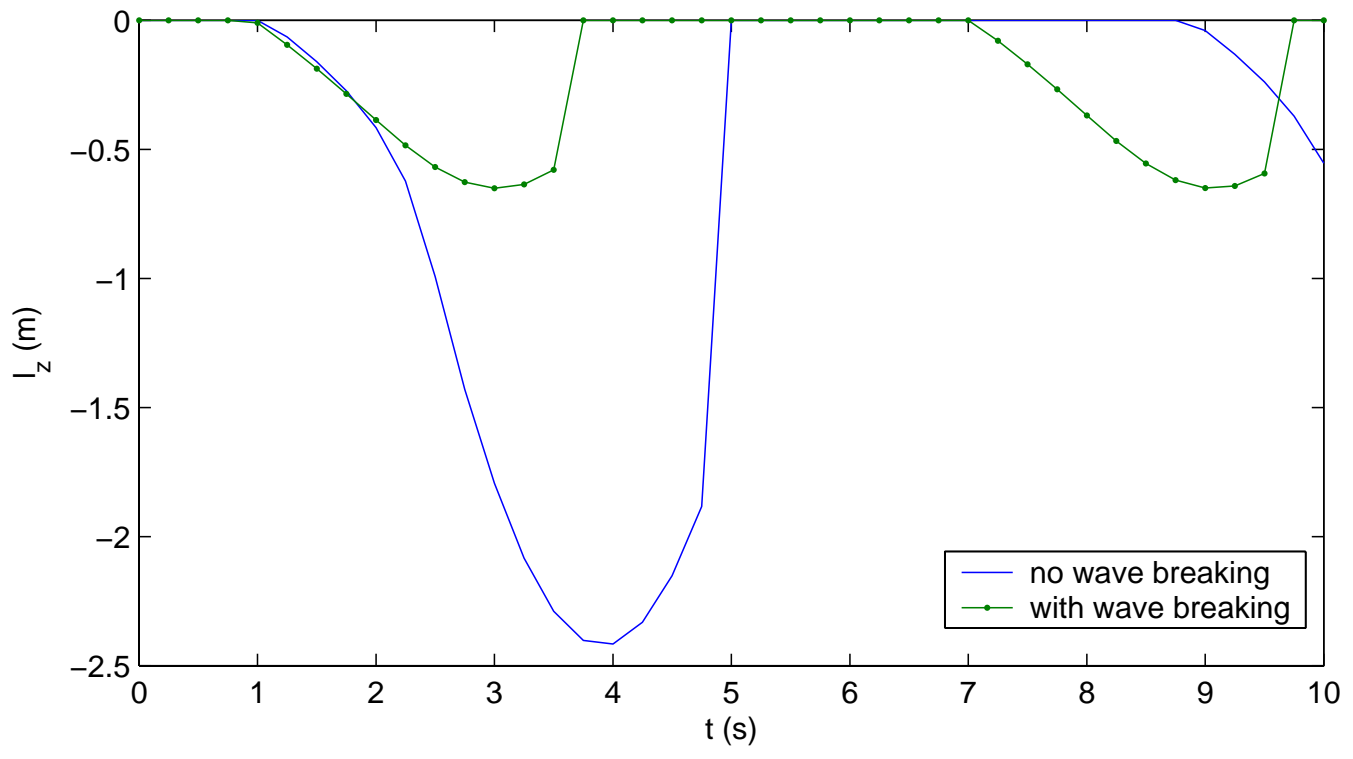

Figure 8(b) 

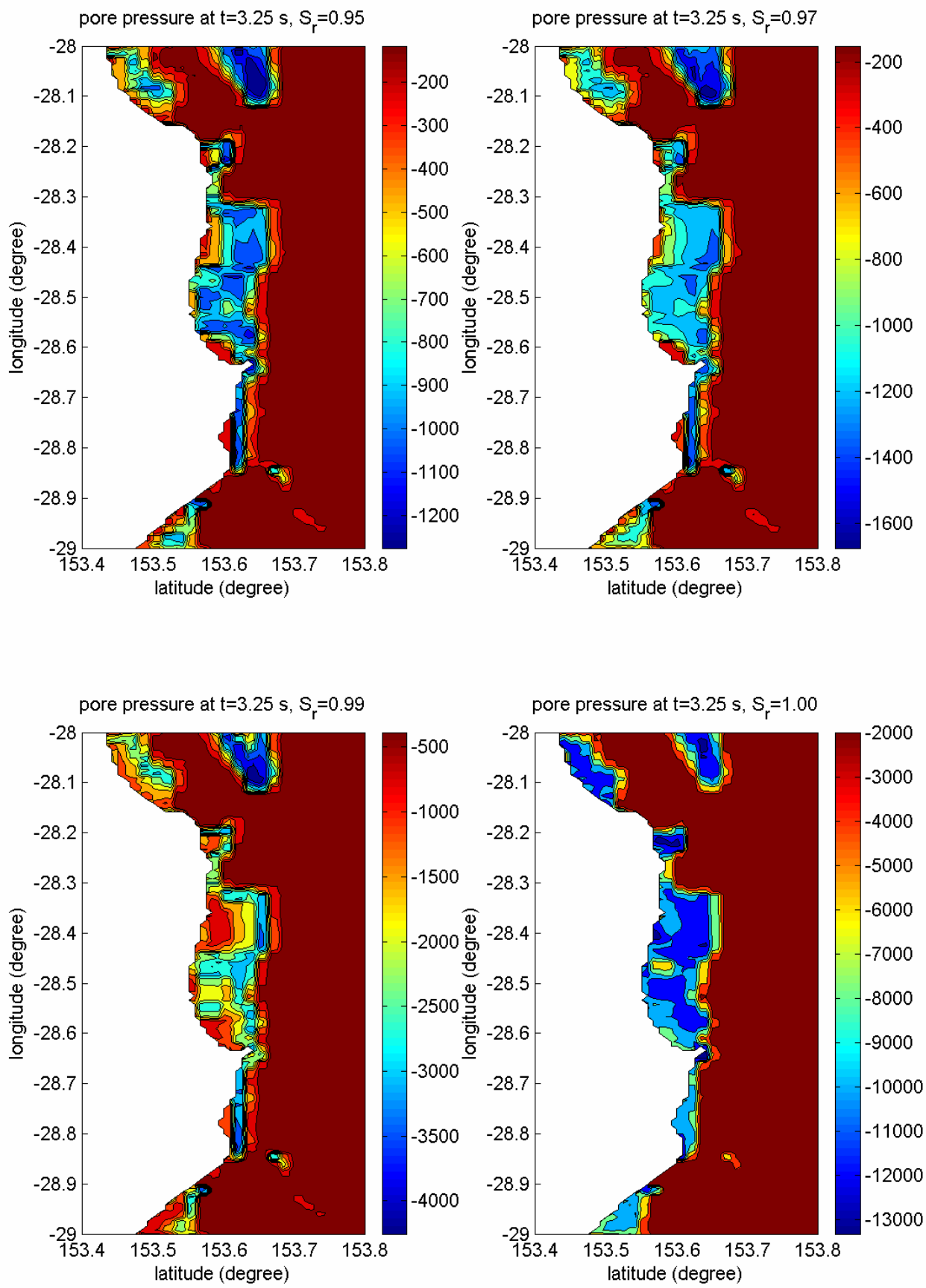

Figure 9 


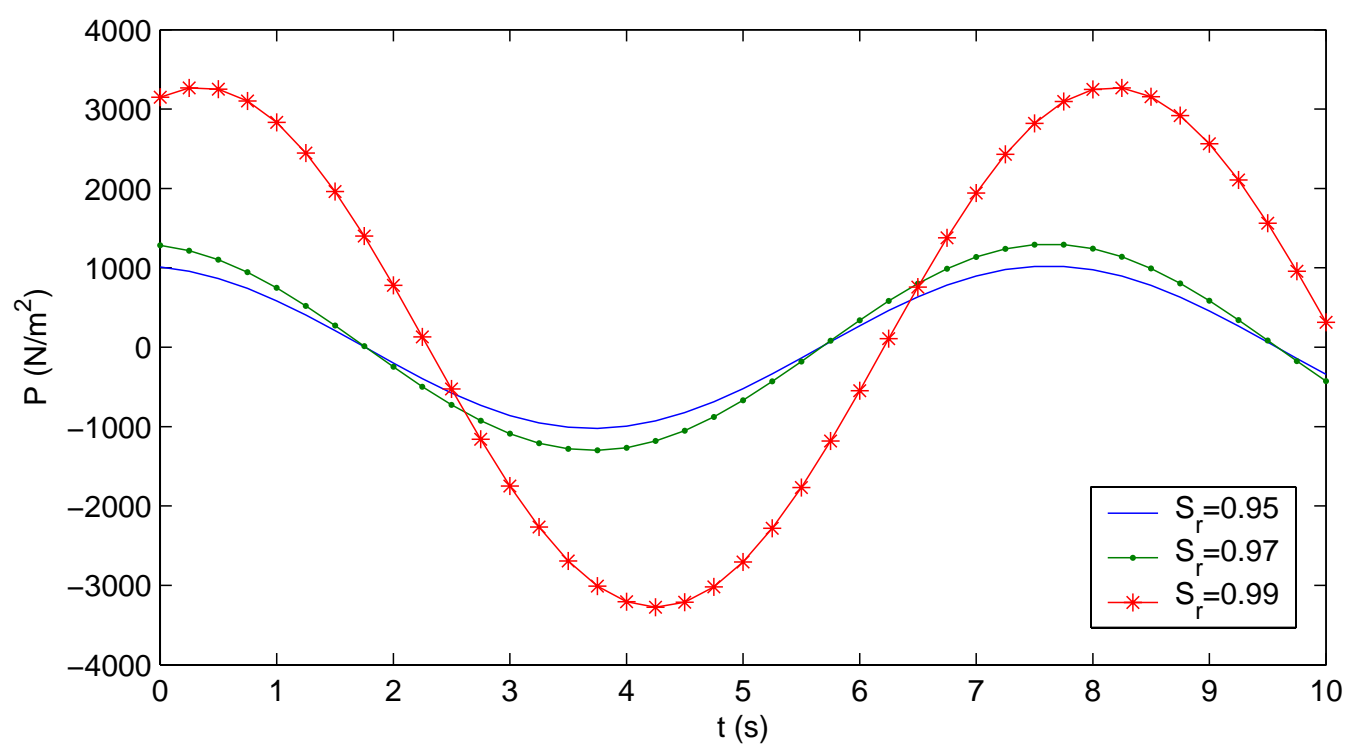

Figure 10(a)

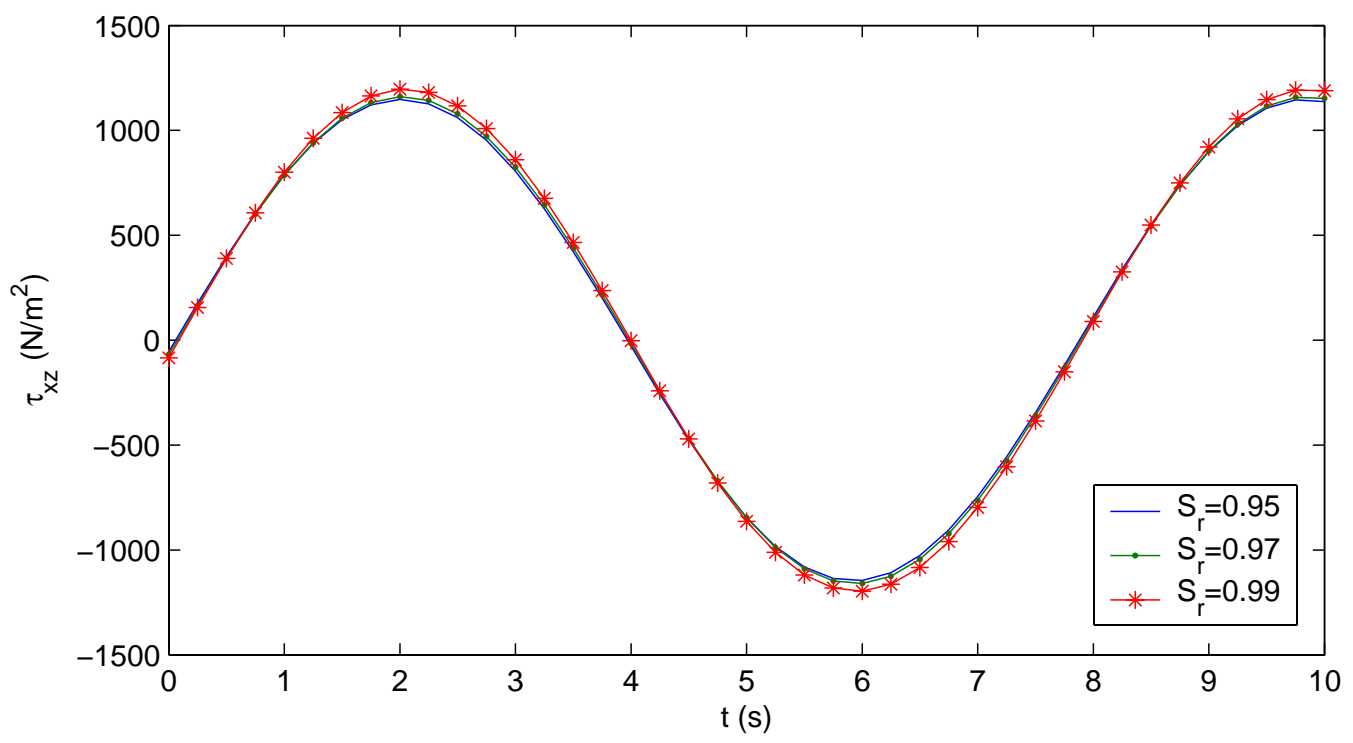

Figure 10(b) 


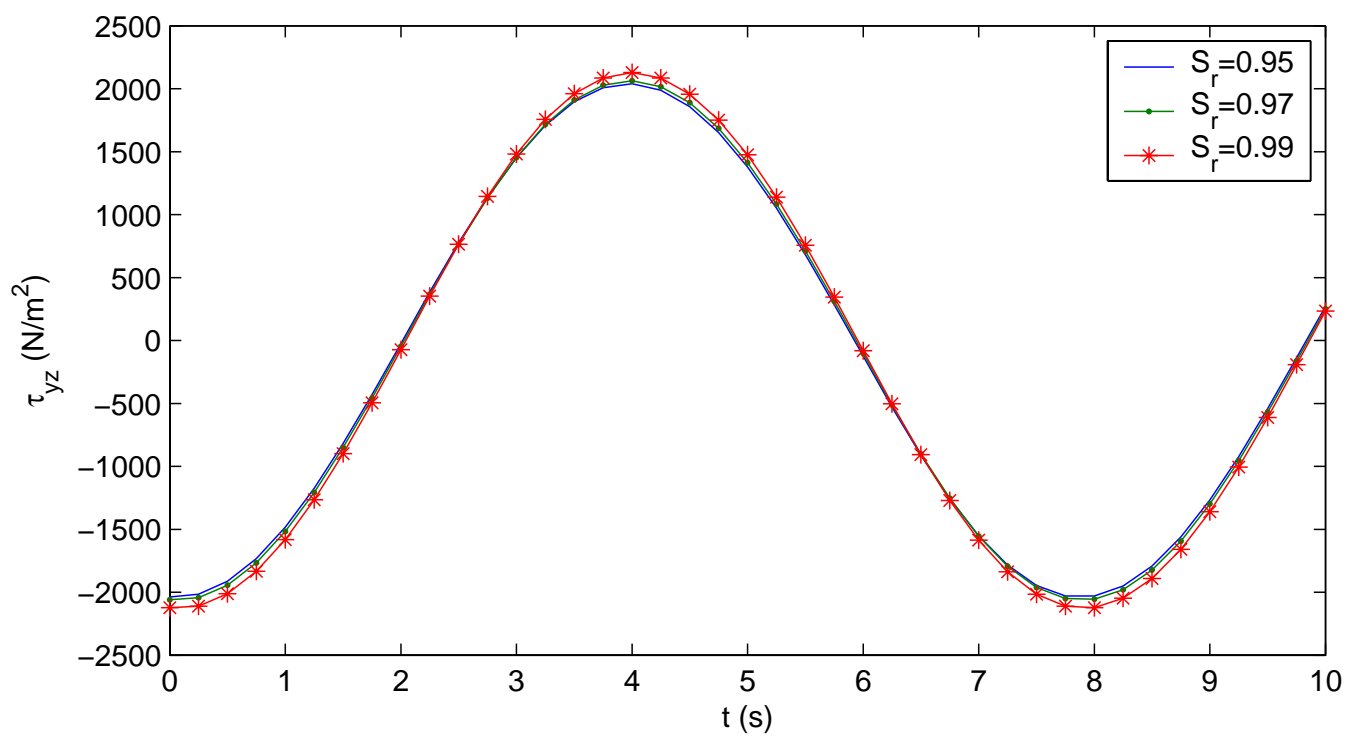

Figure 10(c)

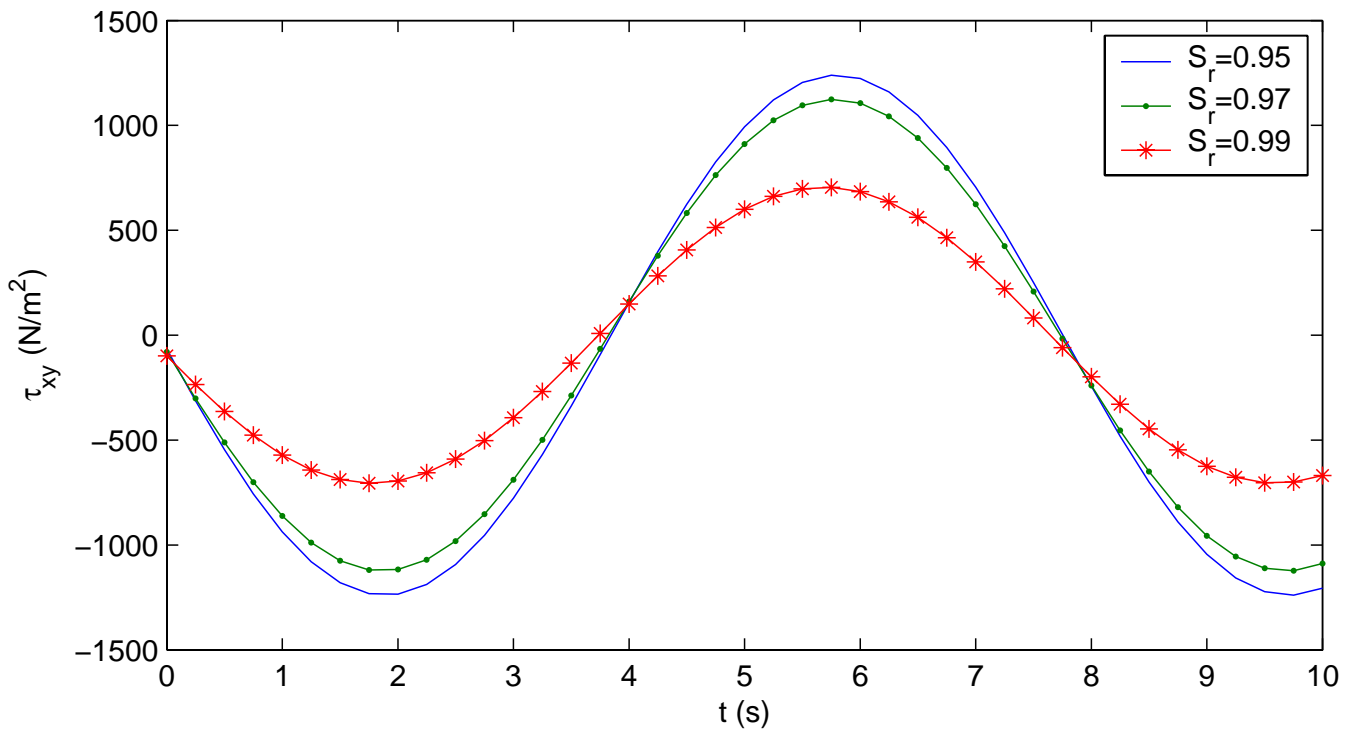

Figure 10(d) 

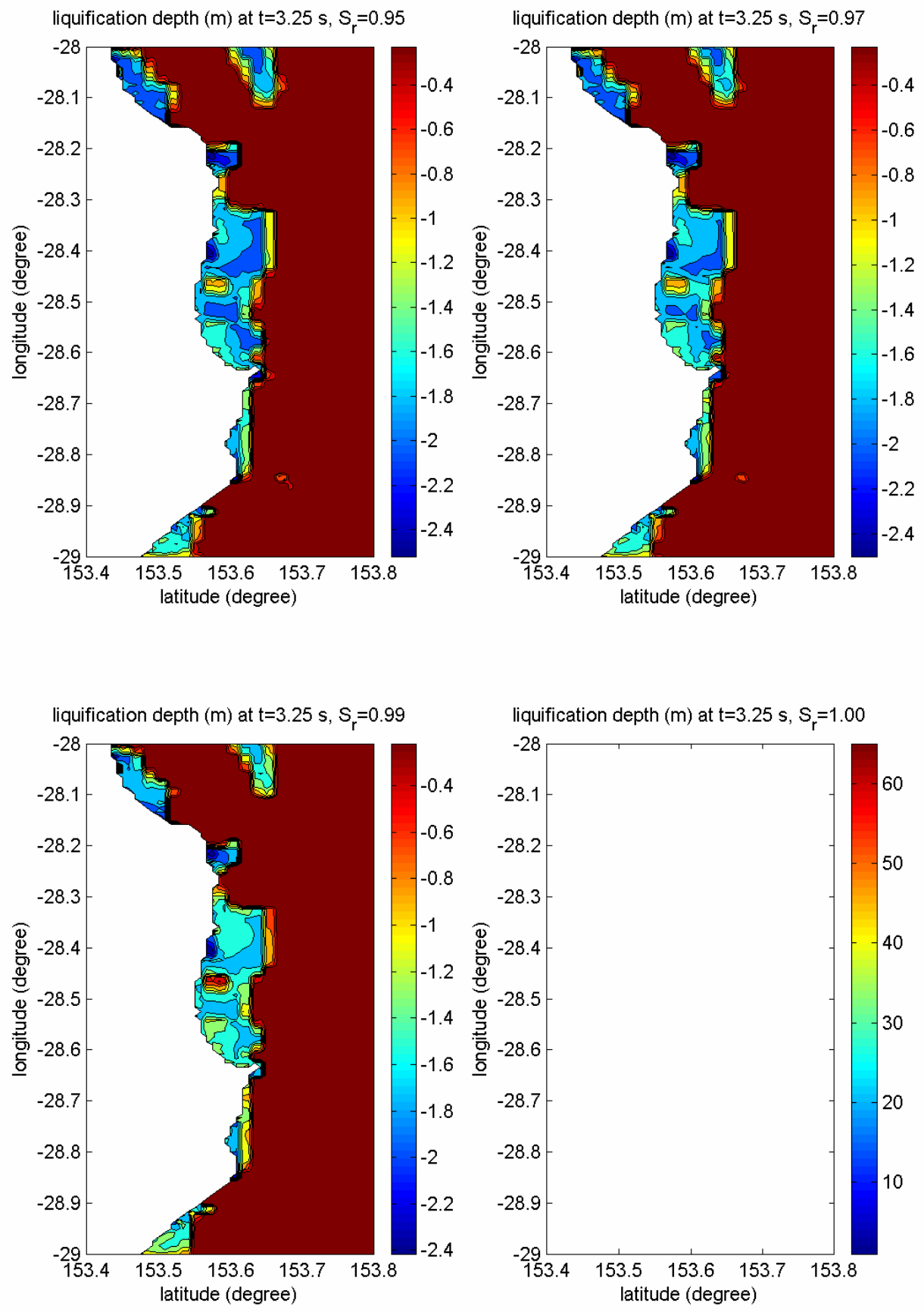

Figure 11 (a) 


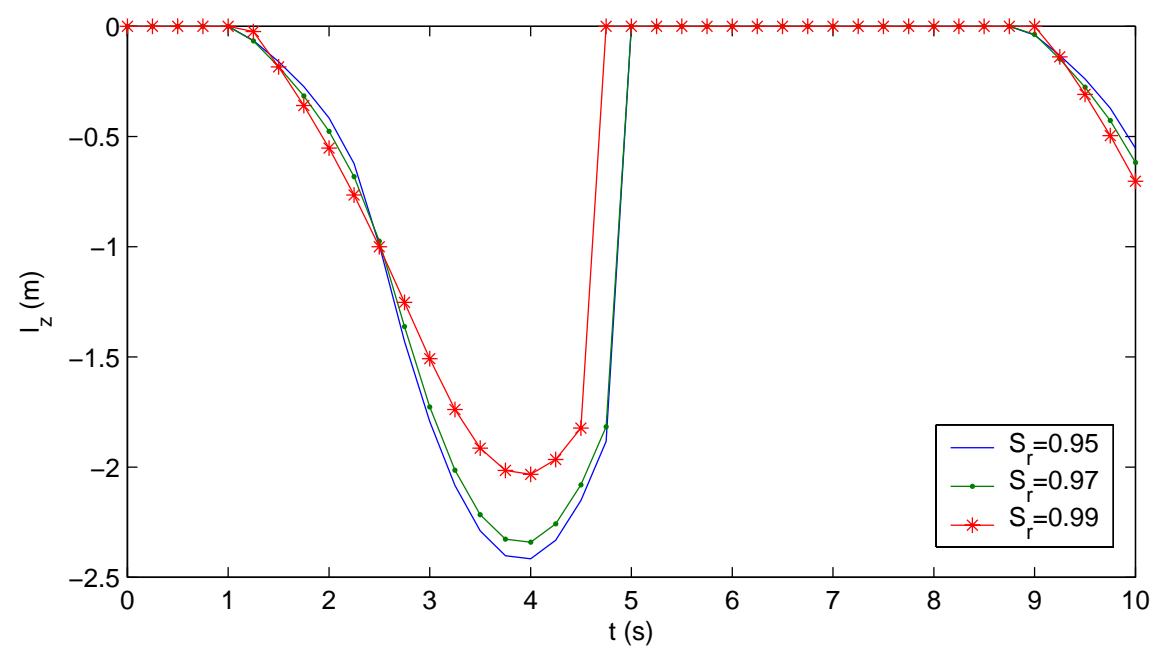

Figure 11(b) 

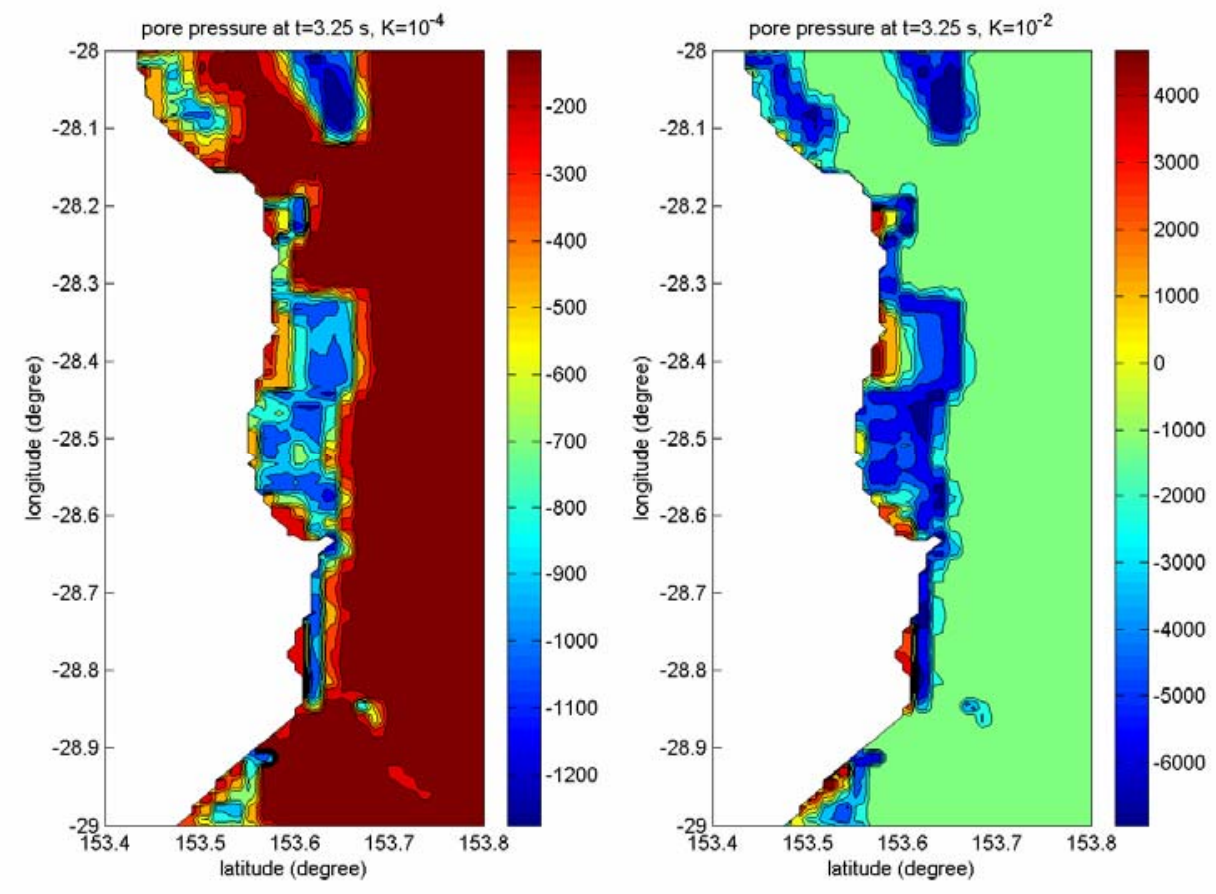

Figure 12 


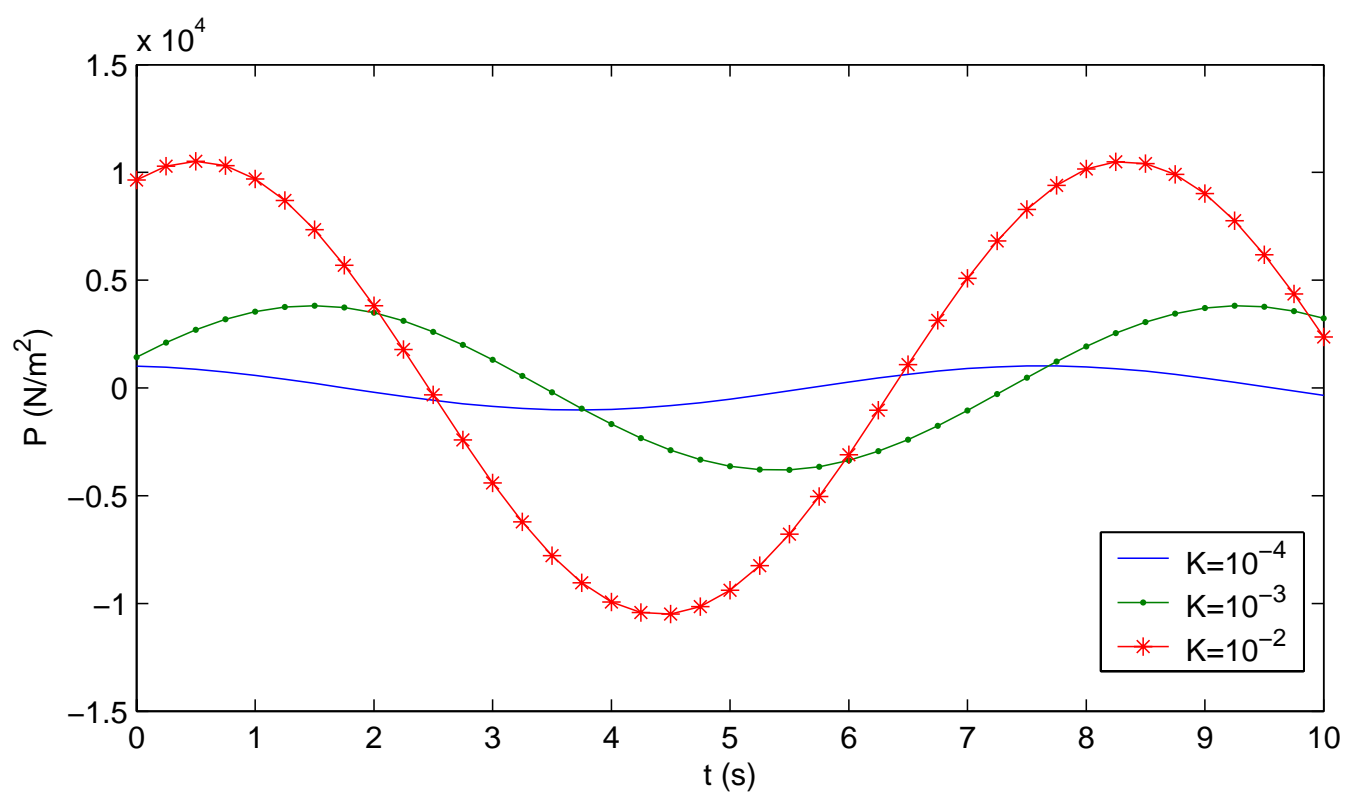

Figure 13 (a)

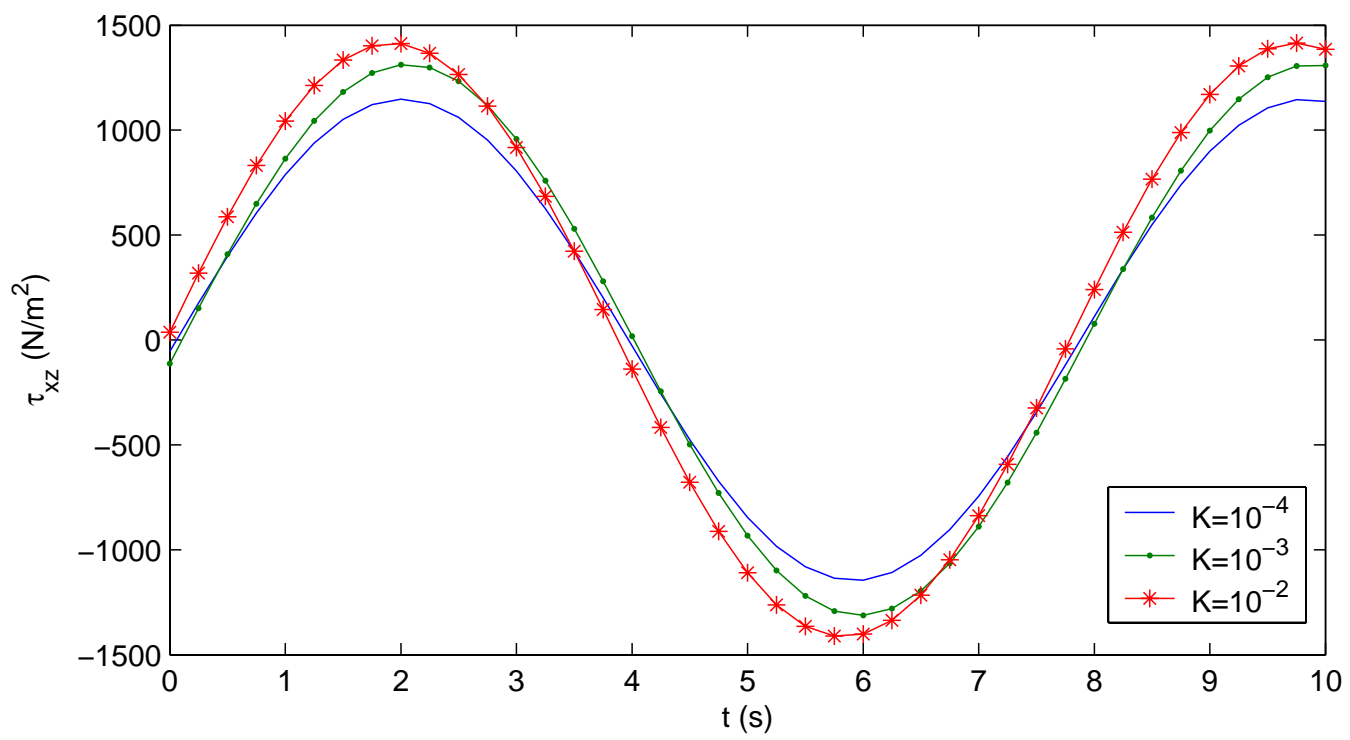

Figure 13(b) 


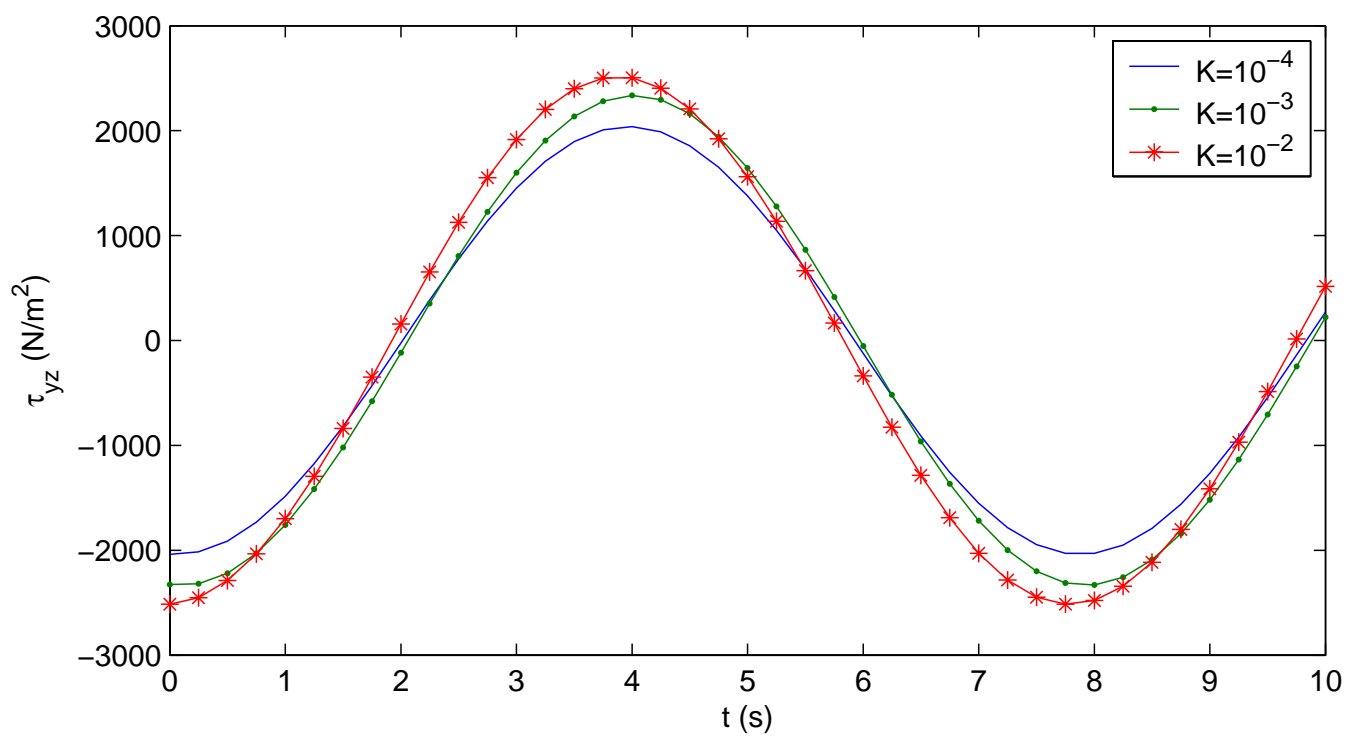

Figure 13(c)

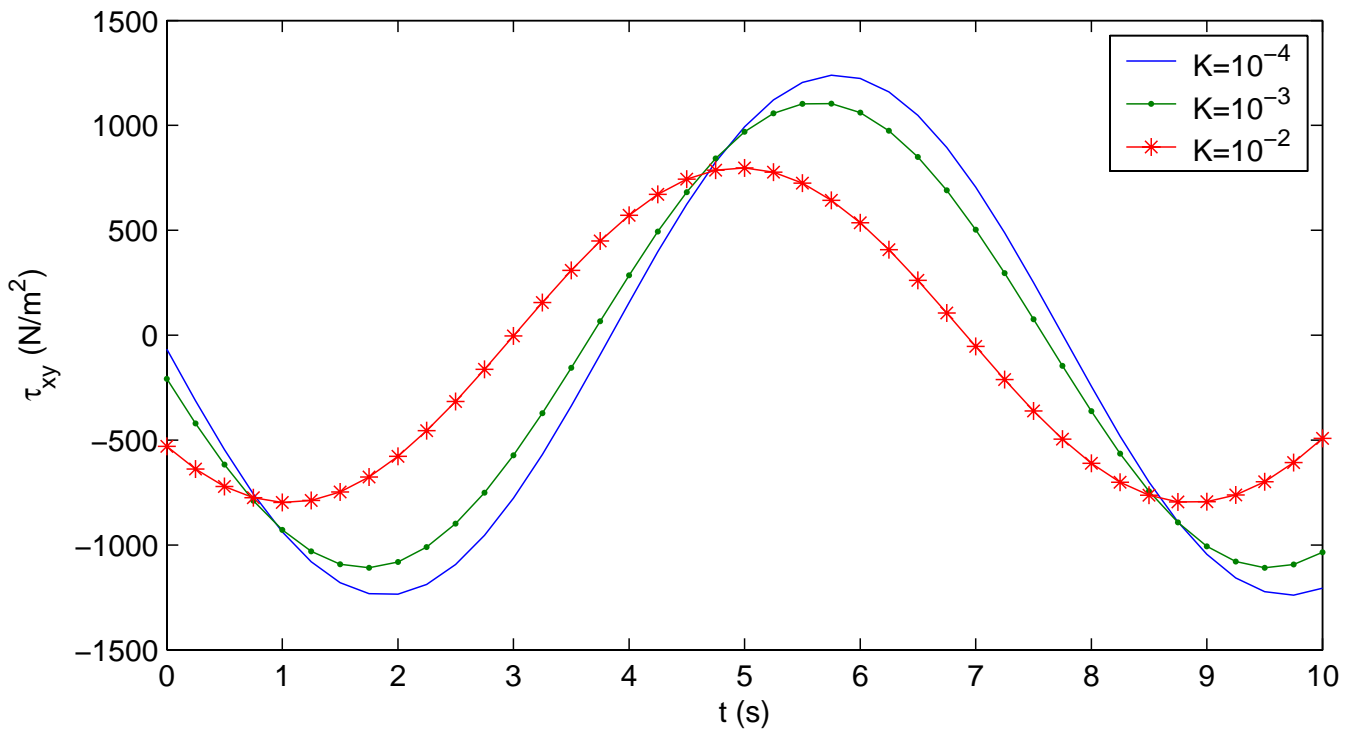

Figure 13 (d) 

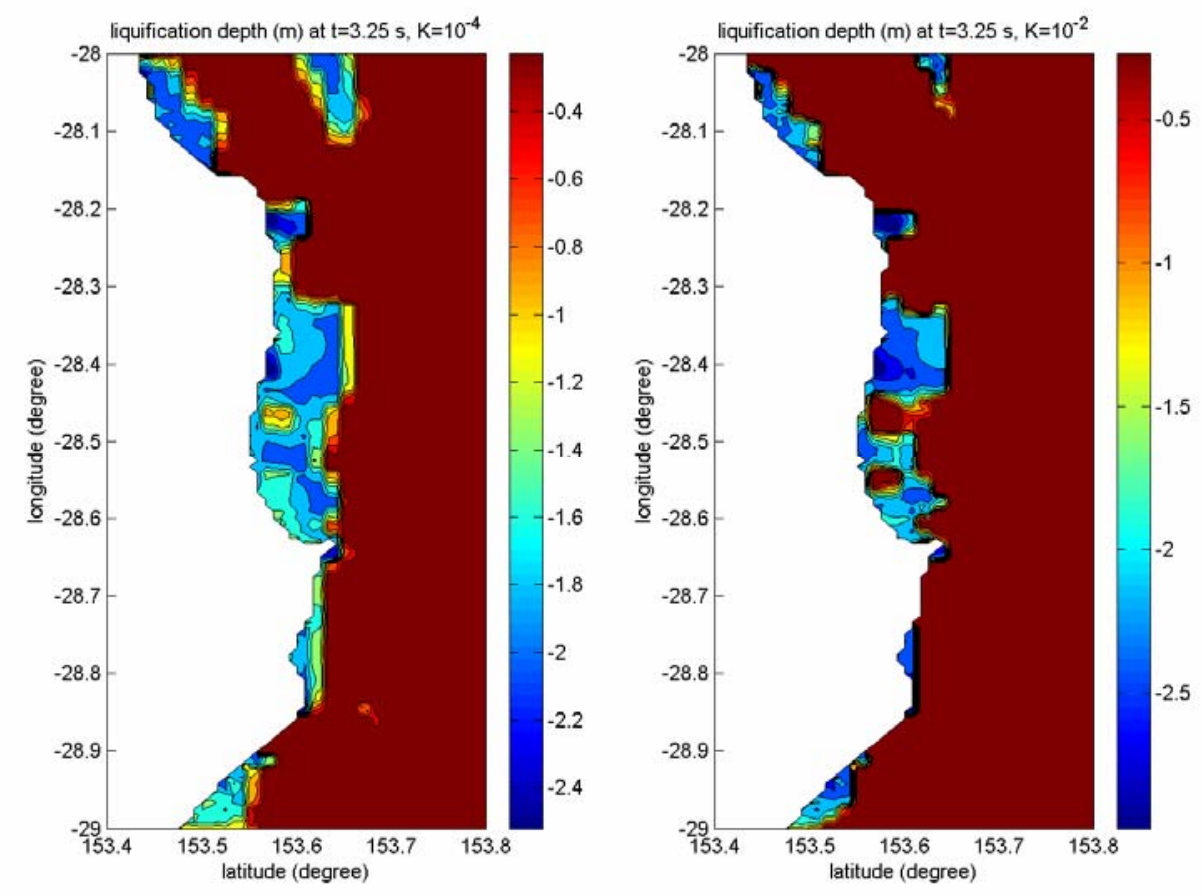

Figure 14(a)

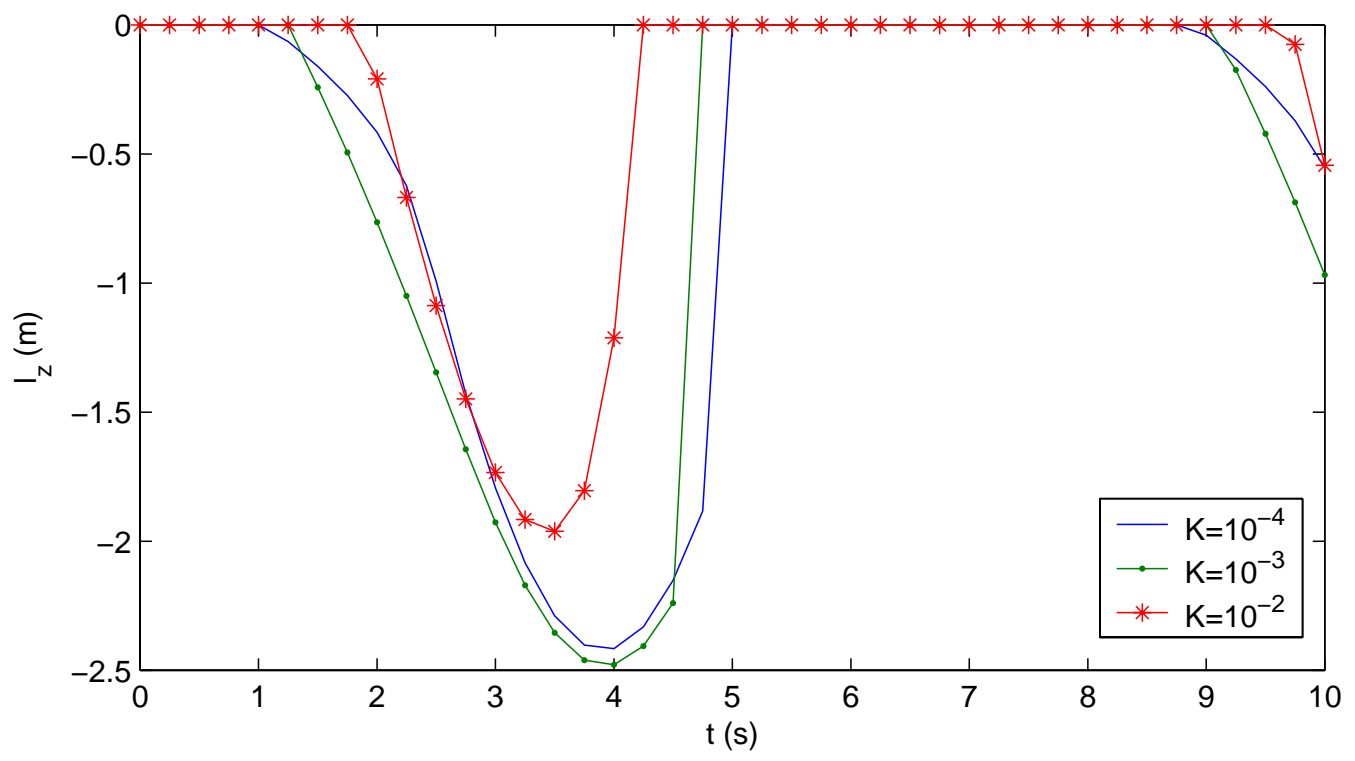

Figure 14(b) 
Table 1: Input data of numerical models

Parameter $\quad$ Values

Grid size in the $(x, y)$ direction $\quad(1000,1000) \mathrm{m}$

Grid number in the $(x, y)$ direction $\quad(61,121)$

Wind speed $20 \mathrm{~m} / \mathrm{sec}$

Wind direction 135 degree

Wave frequency (lowest, highest) $\quad(0.0521,1) \mathrm{Hz}$

Number of frequency $\quad 31$

Significant wave height at boundaries $\quad 3 \mathrm{~m}$

Peak wave period at boundaries $\quad 10 \mathrm{sec}$

Soil permeability $\quad 0.01-0.0001 \mathrm{~m} / \mathrm{sec}$

Shear modulus $\quad 10^{7} \mathrm{~N} / \mathrm{m}^{2}$

$\begin{array}{ll}\text { Poisson's ratio } & 0.3\end{array}$

$\begin{array}{ll}\text { Soil porosity } & 0.4\end{array}$ 